\title{
Activation of hypoxia signaling induces phenotypic transformation of glioma cells: implications for bevacizumab antiangiogenic therapy
}

\author{
Hui Xu ${ }^{1}$, Shervin Rahimpour ${ }^{2}$, Cody L. Nesvick ${ }^{2}$, Xu Zhang ${ }^{1}$, Jingyun Ma $^{1}$, Min \\ Zhang1, Ge Zhang $^{3}$, Li Wang1, Chunzhang Yang², Christopher S. Hong ${ }^{2}$, Anand V. \\ Germanwala ${ }^{4}$, J. Bradley Elder5, Abhik Ray-Chaudhury², Yu Yao ${ }^{6}$, Mark R. Gilbert ${ }^{7}$, \\ Russell R. Lonser ${ }^{5}$, John D. Heiss ${ }^{2}$, Roscoe O. Brady ${ }^{2}$, Ying Mao ${ }^{6}$, Jianhua Qin ${ }^{1}$ and \\ Zhengping Zhuang ${ }^{2}$ \\ ${ }^{1}$ Division of Biotechnology, Dalian Institute of Chemical Physics, Chinese Academy of Sciences, Dalian, China \\ ${ }^{2}$ Surgical Neurology Branch, National Institute of Neurological Disorders and Stroke, Bethesda, Maryland, USA \\ 3 Department of Immunology, Dalian Medical University, Dalian, China \\ ${ }^{4}$ Department of Neurological Surgery, Loyola University Medical Center, Chicago, Illinois, USA \\ ${ }^{5}$ Department of Neurological Surgery, The Ohio State University Medical Center, Columbus, Ohio, USA \\ ${ }^{6}$ Department of Neurosurgery, Huashan Hospital, Shanghai Medical College, Fudan University, Shanghai, China \\ 7 Department of Neuro-Oncology, Division of Cancer Medicine, The University of Texas MD Anderson Cancer Center, Houston, \\ Texas, USA \\ Correspondence to: Ying Mao, email: yingmao168@hotmail.com
}

Jianhua Qin, email: jhqin@dicp.ac.cn

Zhengping Zhuang, email: zhuangp@ninds.nih.gov

Keywords: glioblastoma, bevacizumab, epithelial-mesenchymal transition, pathologic angiogenesis, hypoxia-inducible factor Received: February 12, $2015 \quad$ Accepted: February 19, $2015 \quad$ Published: March 14, 2015

This is an open-access article distributed under the terms of the Creative Commons Attribution License, which permits unrestricted use, distribution, and reproduction in any medium, provided the original author and source are credited.

\section{ABSTRACT}

Glioblastoma (GBM) is the most common and deadly primary brain tumor in adults. Bevacizumab, a humanized monoclonal antibody against vascular endothelial growth factor (VEGF), can attenuate tumor-associated edema and improve patient symptoms but based on magnetic resonance imaging, is associated with nonenhancing tumor progression and possibly gliosarcoma differentiation. To gain insight into these findings, we investigated the role of hypoxia and epithelial-mesenchymal transition (EMT)-associated proteins in GBM. Tumor markers of hypoxia and EMT were upregulated in bevacizumab-treated tumors from GBM patients compared to untreated counterparts. Exposure of glioma cells to $1 \%$ oxygen tension increased cell proliferation, expression of EMT-associated proteins and enhanced cell migration in vitro. These phenotypic changes were significantly attenuated by pharmacologic knockdown of hypoxia-inducible Factor 1a (HIF1a) or HIF2a, indicating that HIFs represent a therapeutic target for mesenchymal GBM cells. These findings provide insights into potential development of novel therapeutic targeting of angiogenesisspecific pathways in GBM.

\section{INTRODUCTION}

Glioblastoma (GBM) is the most common adult primary nervous system tumor. Despite advances in surgical resection, radiation and chemotherapy, GBM remains one of the most deadly human neoplasms. GBM patients have a median survival of 12 to 15 months and new therapies are desperately needed [1]. Bevacizumab, a humanized monoclonal antibody against vascular endothelial growth factor (VEGF), has been shown to improve progression-free survival in patients with recurrent glioblastoma [2-4]. As one of the most highly 
vascular cancers, GBMs express high levels of VEGF, particularly in areas of necrosis and hypoxia $[5,6]$. The increased levels of VEGF expression and vascular density in GBM make angiogenesis an attractive therapeutic target. Clinical trials have demonstrated that bevacizumab is a therapeutic option for recurrent GBM patients who have failed previous radiation and chemotherapy $[3,7]$.

Angiogenesis inhibitors, including bevacizumab, produce demonstrable transient clinical and radiological benefits for patients with a variety of cancer types including GBM [8]. However, in 40 to $60 \%$ of cases, initial responses are frequently followed by dramatic progression of disease [2, 9]. Consequently, overall survival has not been significantly improved with antiangiogenic therapy and is associated with an increased rate of transformation to secondary gliosarcoma $[2-4,9,10]$. Recent data indicate that resistance to bevacizumab antiangiogenic therapy can be due to evasive (upregulation of alternative pro-angiogenic pathways) or intrinsic (genomic constitution) changes within the neoplasm [11]. These findings potentially make combinatorial strategies, specifically integration of both anti-angiogenic therapy and anti-resistance mechanisms, particularly attractive for managing GBM.

Critical to a deeper understanding of the pathobiology of therapeutic resistance and progression will be insights into the effects of anti-angiogenic therapy in GBM. To better understand the mechanisms that underlie tumor cell invasiveness and progression of disease during/following anti-angiogenic therapy, we examined the phenotypic changes of GBM cells in the setting of induced hypoxia. Specifically, bevacizumabinduced inhibition of VEGF can trigger intratumoral hypoxia and initiate compensatory survival pathways, namely upregulation of hypoxia-inducible factors (HIFs) [12]. Data indicate that HIF stabilization enhances tumor cell invasion, cell growth and cell survival and thus serves a critical role in modulating tumor aggression [13-22]. This may underlie the clinical and radiographic findings associated with anti-angiogenic therapy in GBM patients.

Based on the emerging clinical and imaging findings in recurrent GBM patients treated with bevacizumab, we hypothesized that the lack of improved overall survival in these patients is modulated through the activation of HIFmediated survival pathways. To test this hypothesis, we analyzed expression levels of HIF down-stream effectors and epithelial-to-mesenchymal (EMT) markers as well as microfluidic invasion assays of GBM cells under normoxic and hypoxic conditions. Moreover, glioma cell phenotype and migration were analyzed following HIF inhibition and gain-of-function to investigate the role of HIFs in tumor cell aggressiveness/progression. Finally, these findings were correlated with comprehensive immunohistochemical (IHC) analysis of recurrent GBM patients treated with bevacizumab via comparative analysis of tumor tissue before and after treatment.

\section{RESULTS}

\section{Hypoxia and mesenchymal transition in human GBM after anti-angiogenic therapy}

Bevacizumab treatment of recurrent GBM is commonly associated with a decrease in intratumoral enhancement and peri-tumoral edema. The reduction in edema results in alleviation of tumor-associated symptoms (Fig. 1a). However, these effects are transient and the tumor eventually becomes refractory to therapy, demonstrates increased infiltration of surrounding brain. and is associated with transformation to gliosarcoma [10]. To test the hypothesis that anti-angiogenic therapy can induce an EMT-like process through hypoxia in GBM, we analyzed tumor tissues from three recurrent GBM patients for markers of hypoxia and EMT before and after bevacizumab treatment. Tumor histology from Patient 1 was most consistent with GBM before bevacizumab therapy but showed histologic changes consistent with transformation to gliosarcoma after treatment (Fig. 1b). Tumor tissues revealed markedly elevated expression of HIF $1 \alpha$ and EMT markers Slug and Snail (diffuse pattern), suggesting that the hypoxic microenvironment activated an EMT-like process post-bevacizumab therapy.

Brains from Patients 2 and 3 were examined postmortem. While both patients received radiation and temozolomide chemotherapy, Patient 3 also received bevacizumab (Fig. 1c). Compared to the tumor from Patient 2, the bevacizumab-treated tumor (Patient 3) exhibited a marked increase in cellularity, cell proliferation and spindle-shaped mesenchymal morphology. Furthermore, the bevacizumab-treated tumor contained significantly more tumor cells that stained for the EMT markers matrix metalloproteinase 2 (MMP2), Zinc-finger E box-binding homeobox 1 (Zeb1), Zeb2, Snail, Slug and Twist. Sections taken $5 \mathrm{~cm}$ away from the tumor mass revealed occasional single infiltrating tumor cells positive for Ki67 and each of the EMT markers, but the scarce number of infiltrating cells precluded any between-tumor comparisons.

\section{Hypoxia enhances GBM cell proliferation}

Given that antiangiogenic therapy can be associated with induction of a hypoxic phenotype and development of gliosarcoma, we hypothesized that exposure to hypoxia would enhance proliferation and mesenchymal change in GBM cell lines. U87 and U251 human GBM cells and C6 rat glioma cells were cultured in $21 \%, 1 \%$ or $0.2 \%$ oxygen for 24 or 48 hours. Expression of the HIF target genes coding for erythropoietin (EPO), vascular endothelial growth factor A (VEGFA), endothelin 1 (EDN1) and glucose transporter 1 (GLUT1) were markedly increased 
in both a time- and oxygen concentration-dependent manner, demonstrating robust activation of hypoxia signaling (Fig. 2, Fig. S1). Alternatively, expression of HIF targets was reduced by knockdown of HIF $1 \alpha$ or HIF $2 \alpha$ using small interfering RNA (siRNA) or pharmacologic inhibition (demonstrative of a robust blockade of HIF transcriptional activity).

To assess the effect of hypoxia on glioma cell proliferation, cell proliferation assays on glioma cells exposed to various oxygen concentrations for 24 or 48 hours were performed (Fig. 3). Under 1\% oxygen tension, hypoxia reliably doubled the proliferative capacity of all glioma cell lines tested. This effect was reduced by pharmacological inhibition of HIF $1 \alpha$ and HIF $2 \alpha$.
Notably, inhibition of HIF $2 \alpha$ more potently inhibited cell proliferation at 24 hours, but this effect was diminished by 48 hours. However, incubation at a very low oxygen concentration had the opposite effect with cell proliferation decreasing by roughly $50 \%$ at both time points. Consistent with a regulatory role for HIFs in GBM cell proliferation under hypoxic conditions, treatment with a HIF inhibitor partially rescued cell proliferation. Glioma cells exposed to $0.2 \%$ oxygen for 48 hours and incubated with the HIF $2 \alpha$ inhibitor demonstrated very similar proliferative capacity to cells incubated under normoxic conditions. Consequently, the effect of hypoxia on glioma cell proliferation is both time- and concentration-dependent.
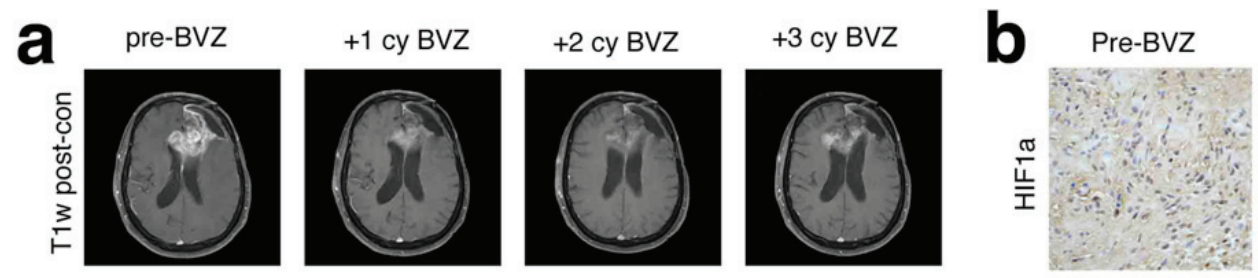

Post-BVZ
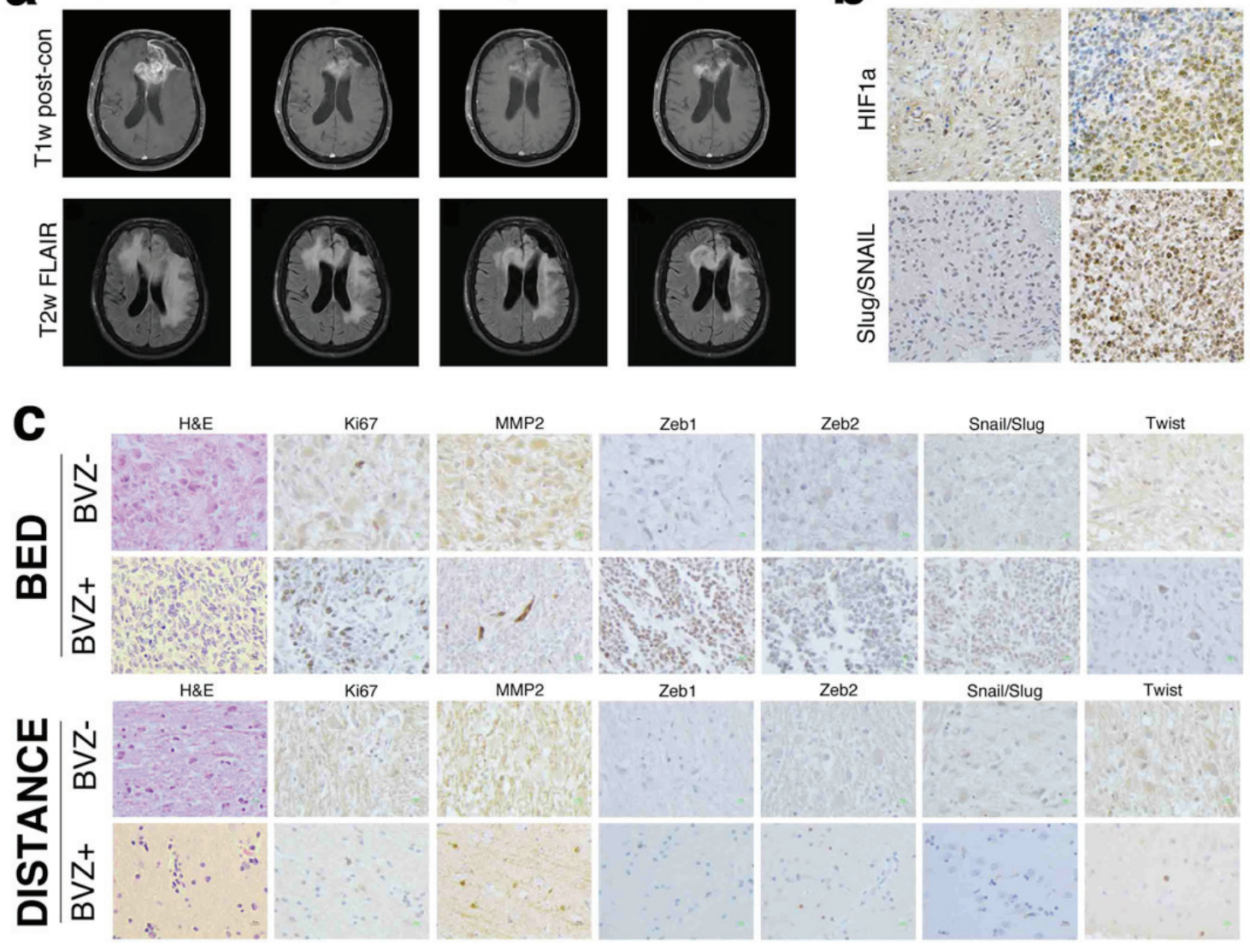

Figure 1: MR imaging and immunhistochemistry of glioblastoma before and after bevacizumab therapy. (a) MR findings in glioblastoma before and after bevacizumab therapy. T1 post-contrast and fluid-attenuated inversion recovery (FLAIR) axial MR images before, after one cycle, two cycles and three cycles or bevacizumab therapy. An initial reduction in the enhancing portions of the residual tumor involving the left frontal lobe and corpus callosum is seen, and a decrease in overall cerebral edema is observed. However, these radiographic improvements are temporary, and later imaging demonstrates increased enhancement and edema. (b) Immunohistochemical staining of HIfl $\alpha$ and the EMT inducers Slug and Snail in a glioblastoma surgical specimen before (left) and after (right) bevacizumab therapy. Following antiangiogenic therapy, an increase in HIF $1 \alpha$ expression is seen concomitant with increased expression of Slug and Snail. Magnification $400 \times$. (c) Hematoxylin and eosin $(\mathrm{H} \& \mathrm{E})$ and immunohistochemical stains of multiple EMT inducers in glioblastomas treated with temozolomide and radiation therapy with and without adjuvant bevacizumab. Compared to the tumor treated with radiation and temozolomide, the bed of the bevacizumab-treated tumor exhibits markedly increased cellularity, Ki67-positivity and a significant increase in the number of spindle-shaped mesenchymal cells. The tumor bed also demonstrated an increase in the number of cells positive for the EMT inducers Zeb1, Zeb2, Slug, Snail, Twist and the EMT marker matrix metalloproteinase 2 (MMP2). Stains performed on sections five centimeters from the tumor bed revealed periodic single infiltrating cells that were often positive for each of the EMT inducers, but no discernible difference was seen between the tumors. Magnification $400 \times$. 
$1 \% \mathrm{O} 224 \mathrm{~h}$

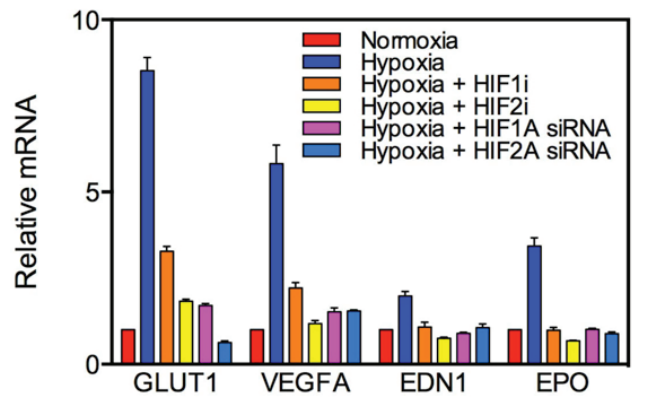

$0.2 \% \mathrm{O} 224 \mathrm{~h}$

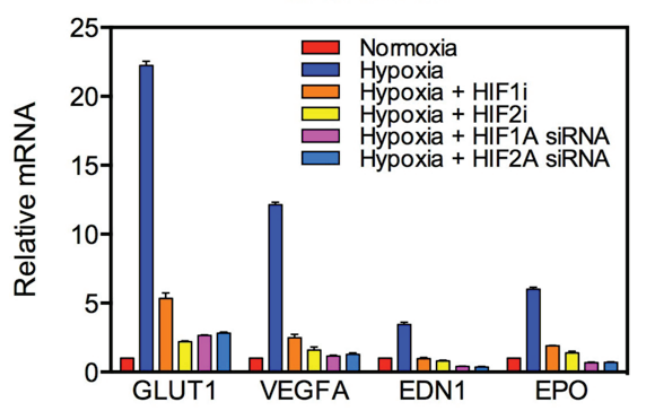

$1 \% \mathrm{O} 248 \mathrm{~h}$

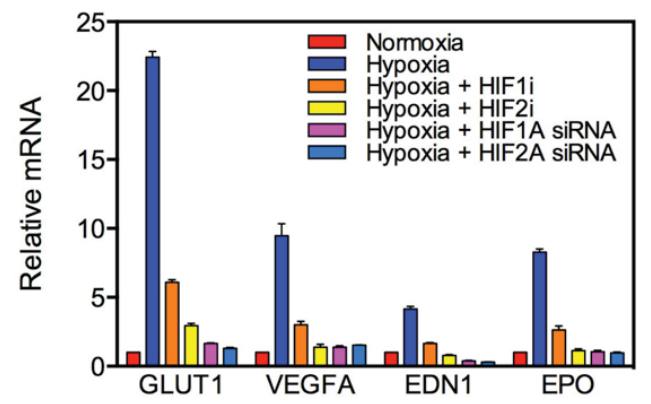

$0.2 \% \mathrm{O} 248 \mathrm{~h}$

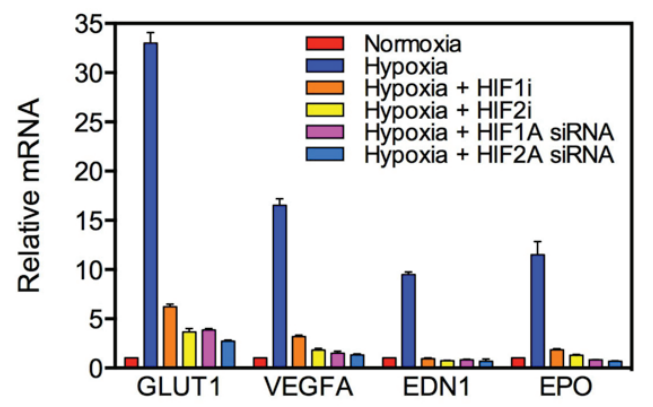

Figure 2: Knockdown of HIF targets by siRNA and pharmacologic agents in U87 glioblastoma cells. Quantitative realtime PCR (qRT-PCR) was used to quantify mRNA expression of the HIF targets GLUT1, VEGFA, EDN1 and EPO following exposure to various oxygen concentrations for 24 (left) or 48 (right) hours. The $y$-axis reflects relative mRNA expression (standard errors of the means [S.E.M.]).

$1 \% \mathrm{O} 224 \mathrm{~h}$

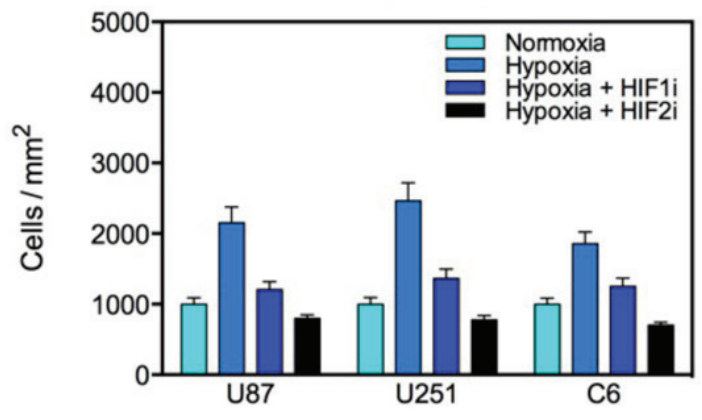

$0.2 \% \mathrm{O} 224 \mathrm{~h}$

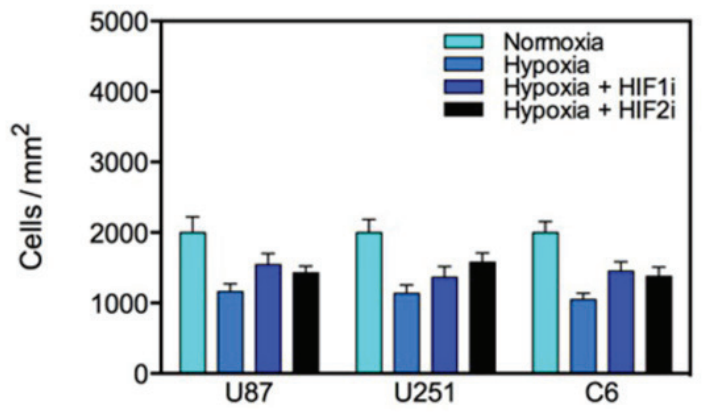

$1 \% \mathrm{O} 248 \mathrm{~h}$

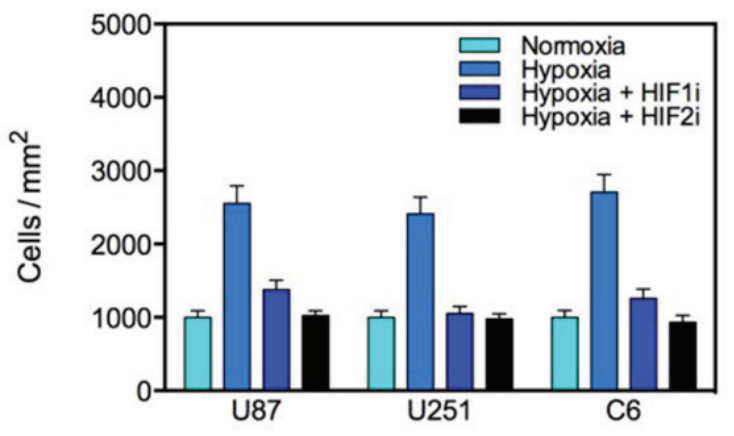

$0.2 \% \mathrm{O} 248 \mathrm{~h}$

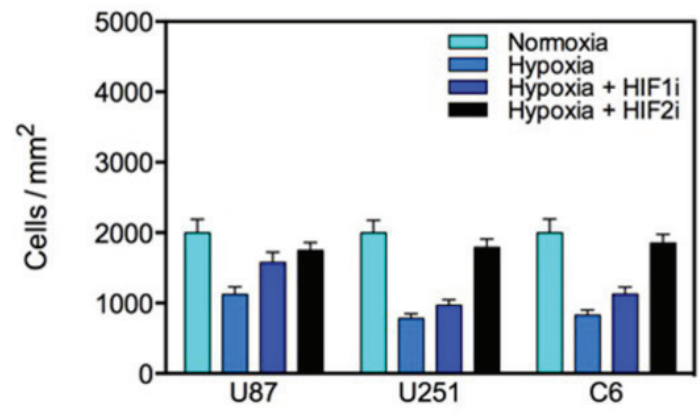

Figure 3: Proliferation of U87, U251 and C6 glioma cell lines under varying oxygen concentrations for 24 or 48 hours. Culture in $1 \%$ oxygen saturation significantly increased glioma proliferation which was reduced by treatment with a HIF $1 \alpha$ or HIF $2 \alpha$ inhibitor. Culture in $0.2 \%$ oxygen saturation significantly reduced the number of viable cells in culture, and this effect was partially reversed by treatment with a HIF inhibitor. The $y$-axis represents the number of cells per square millimeter normalized to controls (S.E.M.). 


\section{Hypoxia induces mesenchymal change in glioma cells}

To test the hypothesis that hypoxia induces mesenchymal change in glioblastoma, we evaluated the expression of the mesenchymal marker vimentin using immunofluorescence under various oxygen concentrations at 24 or 48 hours (Fig. 4a and 4b). Low levels of vimentin were detected under normoxic conditions in each of the cell lines evaluated, indicating some degree of mesenchymal change at baseline. At 24 hours, there was no appreciable change in vimentin expression under $1 \%$ oxygen concentration, and a slight increase was detected under $0.2 \%$ oxygen in U251 cells only. However, hypoxia consistently upregulated vimentin at 48 hours, indicating an oxygen concentration- and time-dependent acceleration of mesenchymal change under hypoxic conditions. This effect was reduced by treatment with a HIF inhibitor. This effect did not appear to differ between HIF $1 \alpha$ and HIF $2 \alpha$.

Mesenchymal transition is governed by a defined set of transcription factors including Slug, Snail and Twist that repress genes coding for cell adhesion proteins, increase expression of MMPs and increase cell motility. To assess the effect of hypoxia on the expression of these transcription factors, we measured mRNA levels of Slug, Snail, Twist, MMP2 and MMP9 under various oxygen concentrations for 24 or 48 hours (Fig. $4 \mathrm{c}$ and S2). Exposure to either $0.2 \%$ or $1 \%$ oxygen saturation consistently upregulated genes associated with EMT in a time- and concentration-dependent fashion, demonstrating robust activation of the EMT program under hypoxia. Upregulation of EMT inducers and MMPs was consistently reduced following siRNA-mediated a

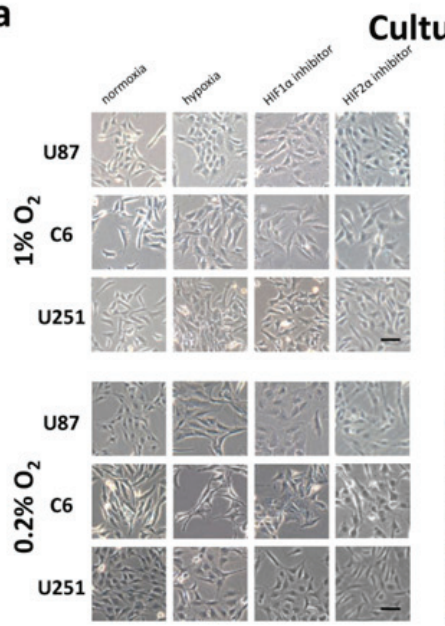

Culture
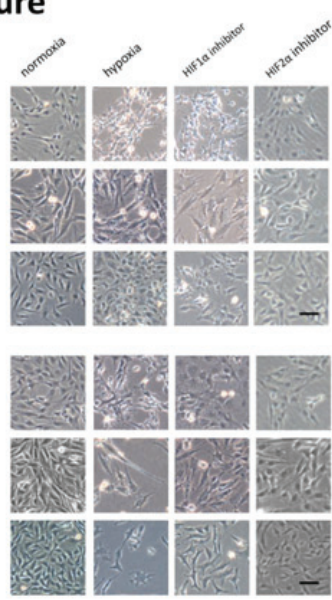

b

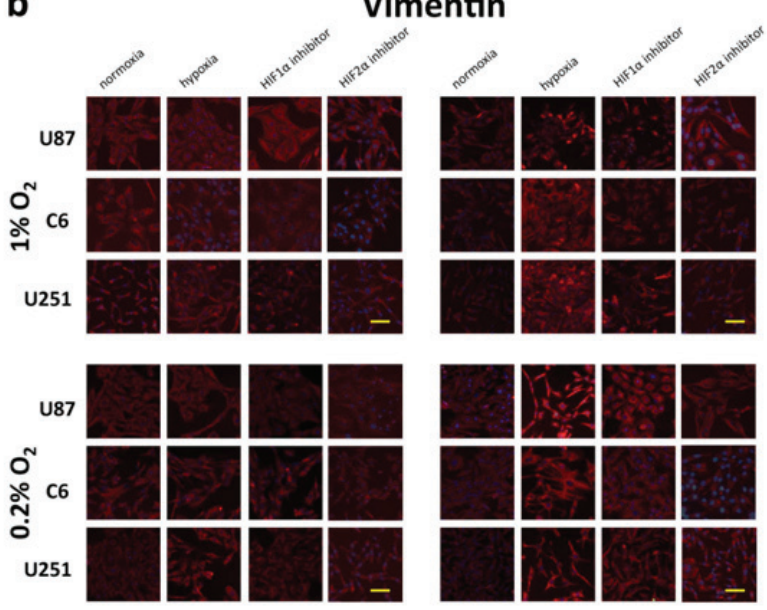

C

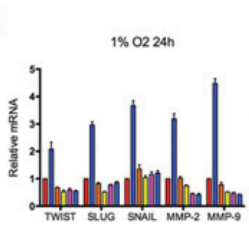

$0.2 \% 0224 \mathrm{~h}$

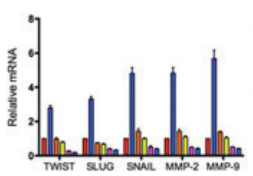

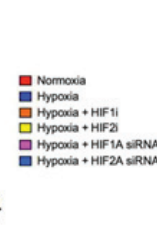

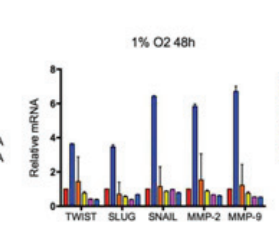

$0.2 \% 0248 h$
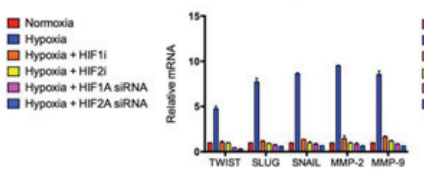
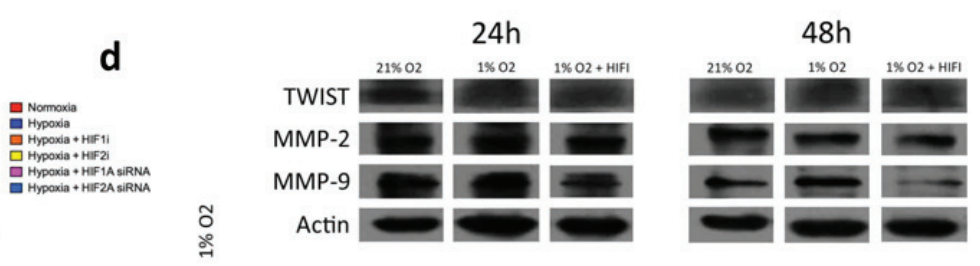

Figure 4: Morphologic changes and expression of EMT inducers and markers in glioma cell lines in response to hypoxia. (a) Phase-contrast microscopy of U87, C6 and U251 glioma cell lines in culture under varying oxygen concentrations and treatment with a pharmacological inhibitor of HIF $1 \alpha$ or HIF $2 \alpha$ as indicated. (b) Immunofluorescent staining for the mesenchymal marker vimentin in each of the cultures from (a). Vimentin expression is upregulated in a time- and oxygen concentration-dependent manner and is significantly reduced by cell treatment with an inhibitor of HIF1 $\alpha$ or HIF2 $\alpha$. (c) Quantitative real-time PCR of multiple EMT inducers, MMP2 and MMP9 extracted from U87 glioblastoma cells under various oxygen concentrations for 24 or 48 hours. Hypoxia consistently increased expression of EMT-associated genes, and this effect was blocked by treatment with HIF $\alpha$ inhibitors. The $y$-axis reflects relative mRNA expression (standard deviation [S.D.]). (d) Immunoblot of Twist, MMP2 and MMP9 extracted from U87 cells under the same conditions as (c). Hypoxia increased expression of each marker at 48 but not 24 hours, and the increase at 48 hours was significantly reduced by treatment with a HIF inhibitor. $\beta$-actin was used as a loading control. 
knockdown of HIF $1 \alpha$ or HIF $2 \alpha$ and after treatment with a HIF $1 \alpha$ or HIF $2 \alpha$ inhibitor.

To determine the time course of EMT-associated protein expression under hypoxia, immunoblots against Twist, Slug, MMP2 and MMP9 were assessed (Fig. 4d and S3). Each investigated target was expressed at high levels at baseline, indicating EMT inducers are present in glioma cell lines under normal conditions. Despite transcriptional upregulation of each target at less than 24 hours of hypoxia, there was no consistent change in Twist, MMP2 or MMP9 expression at 24 hours. However, at 48 hours under hypoxia, each EMT-associated protein was upregulated, and expression was blocked by treatment with a HIF inhibitor. These findings indicate that hypoxia enhances the expression of proteins that induce EMT and expression of these proteins is subject to inhibition by pharmacologic blockade of HIFs.

\section{Hypoxia enhances the migratory capacity of glioma cells}

Mesenchymal transformation confers cells with enhanced migratory ability and is consistent with findings of diffuse spread of non-enhancing GBM on magnetic resonance (MR) imaging. To investigate whether hypoxiainduced mesenchymal transformation of glioma cells results in a migratory phenotype, we evaluated U87 GBM cell migration using a microfluidic chip invasion assay under $21 \%$ or $1 \%$ oxygen saturation (Fig. 5a). For this assay, cells were plated on a two-dimensional main channel, and invasive cells were allowed to migrate into a three-dimensional collagen matrix that more accurately simulated the microenvironment of the cell. Immunofluorescence was then performed to determine the expression of HIF $1 \alpha, \mathrm{HIF} 2 \alpha$ and vimentin in migrated cells. Hypoxia significantly enhanced tumor cell

a

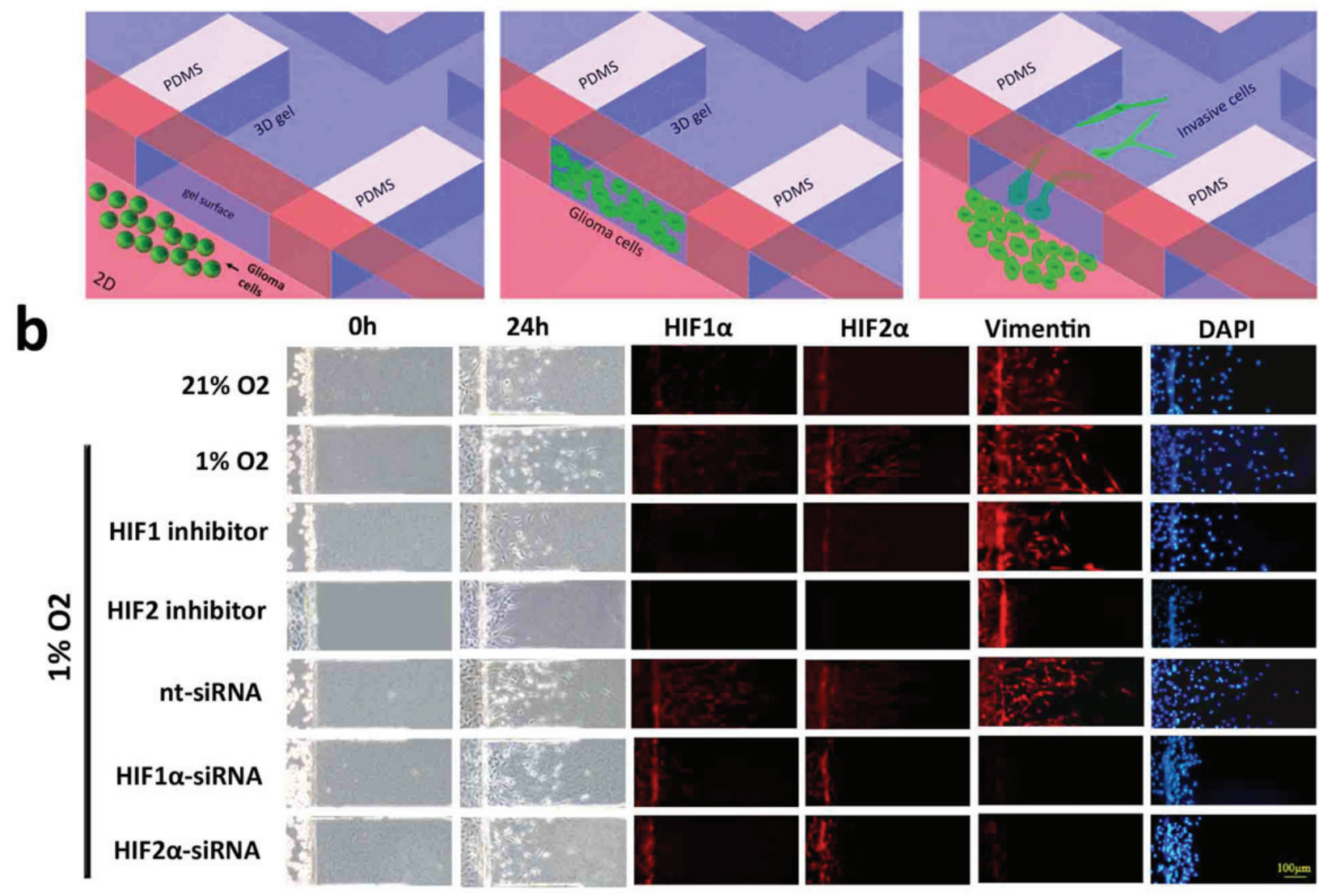

Figure 5: Microfluidic chip migration assay of U87 glioblastoma cells. (a) Schematic diagram of the microfluidic chip migration assay. Cells are placed in a chamber containing either $21 \%$ or $1 \%$ oxygen and allowed to migrate along a three-dimensional collagen-based surface. (b) U87 glioma cell migration following exposure to $21 \%$ (top row) or 1\% oxygen saturation for 24 hours. Immunofluorescent stains against HIF $1 \alpha$, HIF2 or vimentin are shown in red and DAPI is blue. Cells in the bottom five rows were treated with a HIF1 $\alpha$ inhibitor, HIF $2 \alpha$ inhibitor, non-targeting siRNA (nt-siRNA), HIF1 $\alpha$-siRNA or HIF $2 \alpha$-siRNA, as indicated. Hypoxia increased the distance and number of vimentin-positive cells that migrated onto the collagen surface. Total migration was significantly reduced after treatment with a HIF inhibitor and attenuated following HIF knockdown by siRNA. Treatment with a HIF2 inhibitor or siRNA knockdown of HIF1 $\alpha$ or HIF $2 \alpha$ significantly reduced the number of migrating vimentin-positive cells. Scale bar $=100 \mu \mathrm{m}$. 
a
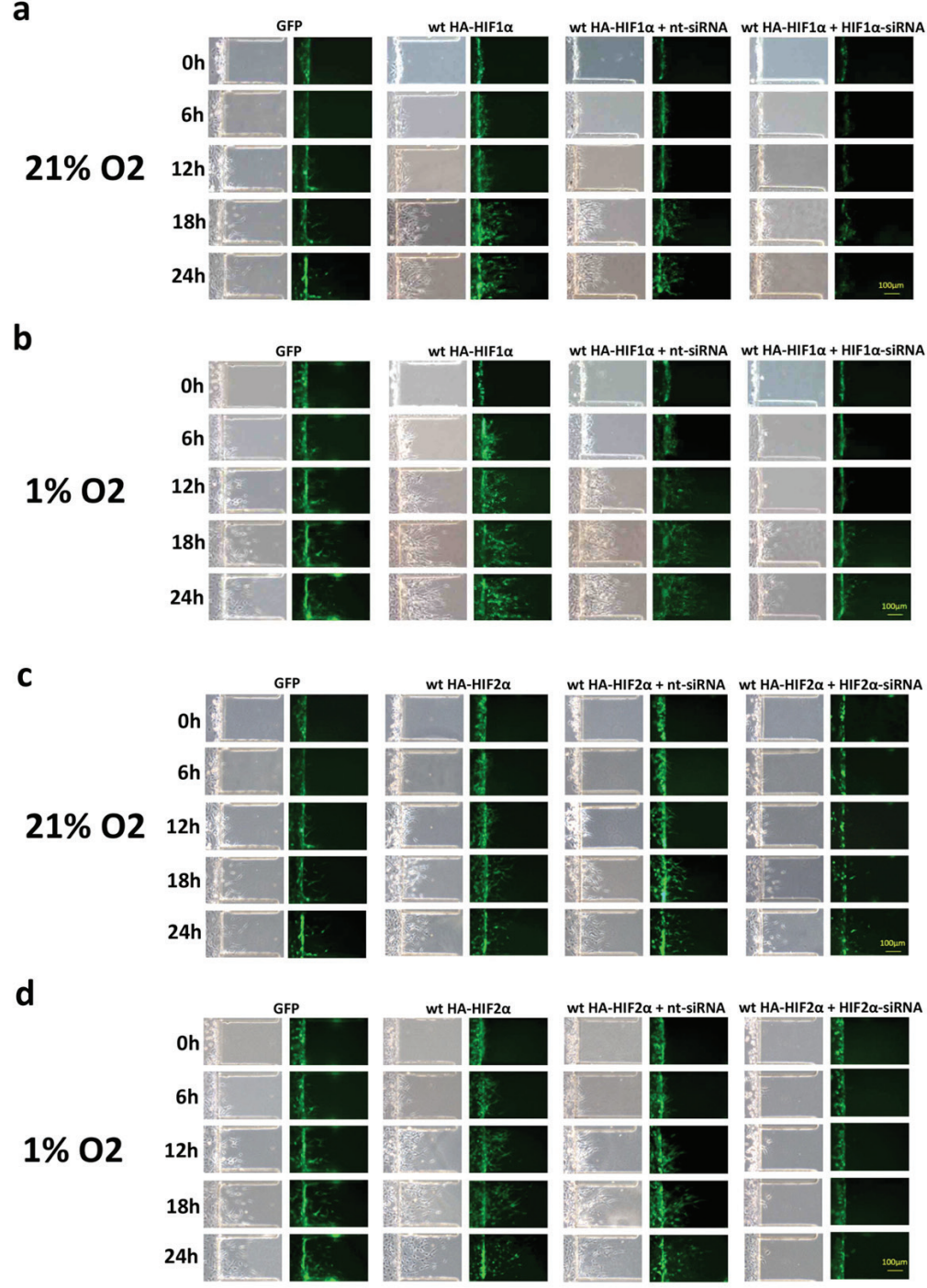

e
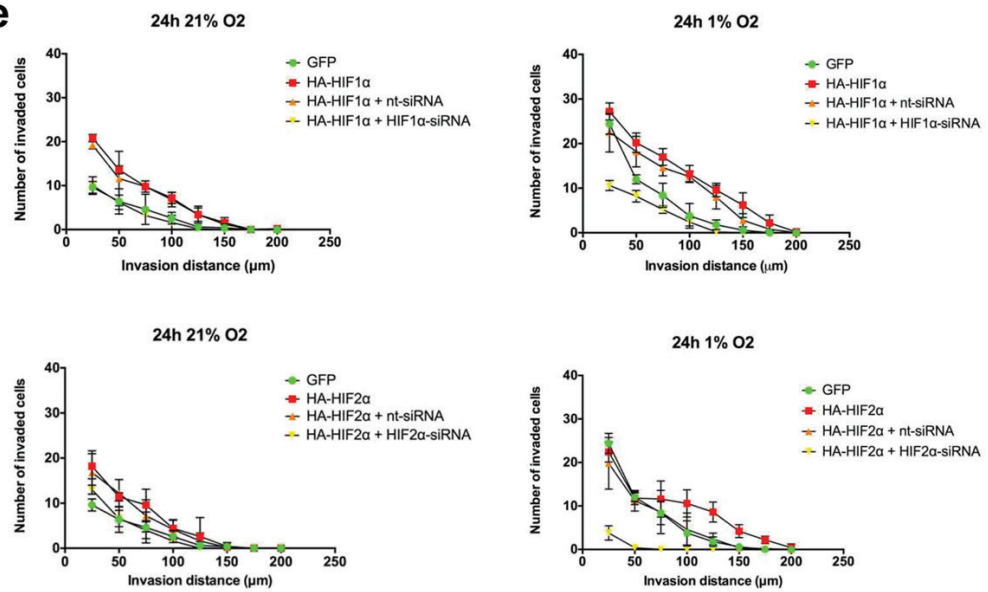

Figure 6: Time-course microfluidic chip migration assay of U87 glioma cells overexpressing HIF1 $\alpha$ and HIF2 $\alpha$. U87 glioma cells were transfected with GFP alone or GFP with a wild-type hemagglutinin-tagged (HA)-HIF1 $\alpha$ gain-of-function construct. HIF $1 \alpha$ gain-of-function cells were either transfected with HA-HIF $1 \alpha$ alone or with nt-siRNA or HIF $1 \alpha$-siRNA. Cell cultures were then placed in the microfluidic chip assay, exposed to $21 \%$ (a) or $1 \%$ (b) oxygen saturation and imaged at $0,6,12,18$ and 24 hours, as indicated. The same set of experiments were performed using HA-HIF2 $\alpha$ and HIF2 $\alpha$-siRNA in (c) and (d). Exposure to either hypoxia or transfection with HIF $1 \alpha$ and HIF $2 \alpha$ gain-of-function constructs enhanced cell migration, and migration was significantly reduced by siRNA knockdown of HIF $1 \alpha$ and HIF $2 \alpha$, respectively. Scale bar $=100 \mu \mathrm{m}$. (e) Quantification of microfluidic chamber invasion assays shown in panels a-d. The $y$-axis reflects the number of invaded cells at each distance at $24 \mathrm{~h}$ (standard deviation [S.D.]). 
migration, and invasive cells exhibited stronger vimentin expression than stationary cells (Fig. 5b). Although siRNA knockdown of HIF $1 / 2 \alpha$ reduced glioma cell migration to levels seen under normoxia, the remaining migratory cells did not express the mesenchymal marker vimentin. Pharmacologic HIF blockade reduced cell migration even further, and this effect was more pronounced following HIF2 $\alpha$ inhibition.

Hypoxia is associated with changes in gene expression and metabolism that collectively contribute to its effect on cell phenotype. To determine the relative contribution of HIF $1 \alpha$ and HIF $2 \alpha$ to glioma cell migration, U87 GBM cells were transfected with hemagglutinintagged HIF $\alpha$-subunit constructs with or without siRNA to a HIF $\alpha$-subunit and then placed under $1 \%$ or $21 \%$ oxygen saturation for 24 hours (Fig. 6). Under normoxic conditions, cells that overexpressed HIF $\alpha$ migrated further than cells transfected with green fluorescent protein (GFP) alone. There was no discernible difference between HIF $1 \alpha$ - and HIF $2 \alpha$-over-expressing cells. Migration was reduced following HIF $1 \alpha$ knockdown and was nearly abolished following HIF $2 \alpha$ knockdown. These findings indicate that both HIF $1 \alpha$ and HIF $2 \alpha$ are individually sufficient to enhance GBM cell migration and that HIF $2 \alpha$, in particular, is necessary for hypoxia-induced cell migration.

To determine whether HIF overexpression is sufficient to induce migration in GBM stem cell populations, we performed a migration assay on neurospheres derived from U87 glioblastoma cells under $21 \%$ or $1 \%$ oxygen that selectively overexpressed HIF $1 \alpha$ or HIF $2 \alpha$ and then determined vimentin expression by immunofluorescence (Fig. 7). Overexpression of either HIF $\alpha$-subunit was sufficient to enhance migration away from the neurosphere, indicating that HIFs are sufficient to stimulate migration out of GBM stem-cell populations.

\section{DISCUSSION}

Hypoxia is a characteristic event in the progression of GBM. Rapidly proliferating tumor cells outstrip their blood supply leading to intratumoral necrosis and induction of the hypoxia signaling pathways. Bevacizumab is an anti-angiogenic therapeutic strategy that can further exacerbate hypoxia in solid tumors. Clinical data indicate that bevacizumab treatment can result in reduced tumor permeability (reduced enhancement on MR imaging) through VEGF-mediated mechanisms [23]. The reduction in vessel permeability results in reduced peritumoral edema and symptom improvement [24, 25]. Emerging data indicate that bevacizumab therapy is associated with non-enhancing (MR imaging) tumor progression and increased risk of gliosarcoma differentiation [10]. The results of the current study demonstrate that hypoxia activates mesenchymal transition and enhances cell motility in GBM in a HIF-dependent manner, and this process can be attenuated by pharmacological blockade of $\mathrm{HIF} \alpha$. Moreover, these data suggest that while HIF1 $\alpha$ may
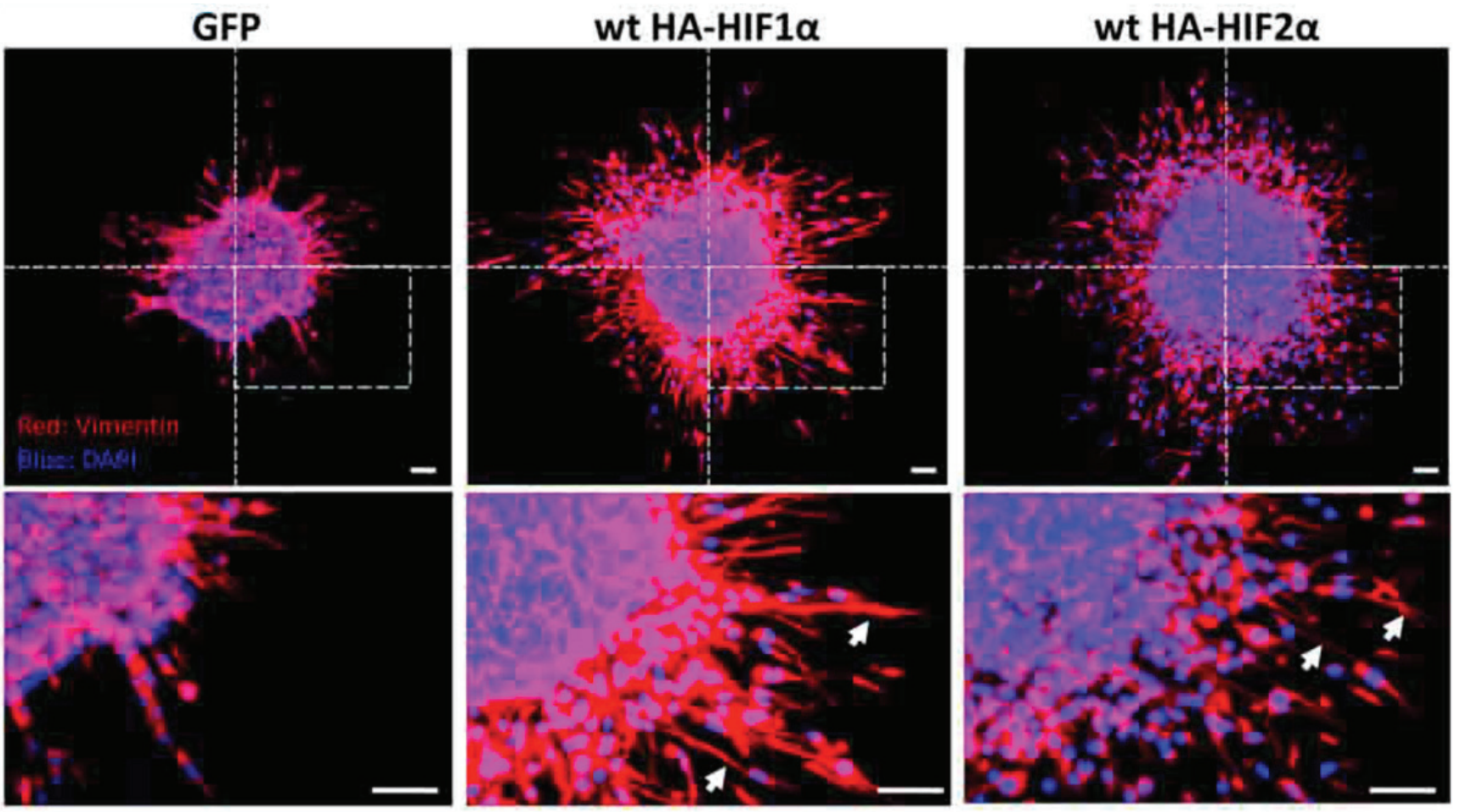

Figure 7: Neurosphere culture of U87 glioma cells under $1 \%$ or $21 \%$ oxygen. Immunofluorescent stain for vimentin in neurosphere cultures. Vimentin-positive spindle-shaped cells (arrows) are visible migrating away from the neurosphere when HIF $1 \alpha$ or HIF2 $\alpha$ is over-expressed under normoxia. DAPI is blue. Scale bar $=100 \mu \mathrm{m}$. 
preferentially enhance cell migration, HIF $2 \alpha$ is necessary for this event to occur.

The term "epithelial-mesenchymal transition" was originally used to describe the process by which a cell adopts a fibroblast-like morphology and migratory phenotype in the process of normal embryonic development [26, 27]. Many of these features are recapitulated in cancer, which led to the observation that EMT is a critical process to cancer progression [26, 27]. Mesenchymal transition (and its converse, mesenchymalepithelial transition) is now a well-described event in epithelial tumors and is increasingly recognized as a key event in non-epithelial cancers such as GBM [2634]. Mesenchymal transition confers multiple oncogenic properties to cancer cells. In addition to enhancing their invasive capacity, EMT endows differentiated cancer cells with the capacity to become stem cells and provides a mechanism for their continued production $[26,27$, $34,35]$. EMT also plays a key role in chemoresistance: Zeb1, for example, controls the susceptibility of GBM to temozolomide by disinhibiting the transcription factor c-MYB, a transcriptional activator of the DNA repair enzyme O-6-Methylguanine DNA Methyltransferase (MGMT) [32].

In the context of new therapeutic approaches to GBM, mesenchymal transition is a key event in resistance to anti-angiogenic therapy $[10,36]$. Recent studies have demonstrated that VEGF antagonists, although providing a temporary reduction in enhancing tumor volume and peritumoral edema, ultimately fail and can induce a mesenchymal phenotype that is more invasive and resistant to therapy than the original tumor [10]. Mechanisms of resistance to VEGF antagonists are multiple. VEGF blockade disinhibits the HGF receptor c-MET, resulting in constitutive activation of tyrosine kinase-ras signaling in GBM [36]. VEGF-resistant cancer cells also secrete significantly more IL-17, resulting in the recruitment of immature immune cells to the tumor microenvironment [37]. VEGF inhibition directly induces tissue hypoxia by relative vasoconstriction, disinhibition of endothelial cell apoptosis and subsequent vessel collapse [38-40]. Intratumoral hypoxia has long been recognized as a sign of successful antiangiogenic therapy in solid tumors but ultimately limits its therapeutic potential by enhancing the proliferative, invasive and stem-like properties of tumor cells [13].

Hypoxia is a potent inducer of EMT. Hypoxiainducible factors activate transcription of multiple EMT-related proteins that leads to a loss of cell-cell adhesion, increased cell motility and evasion from cell cycle arrest $[41,42]$. This process is crucially dependent on HIF stabilization, as EMT in VHL-null renal cell carcinoma occurs in the absence of true hypoxia [41]. Under normoxic conditions, the E3 ubiquitin ligase von Hippel Lindau protein (pVHL) ubiquitinates hydroxylated HIF $\alpha$-subunits, targeting them for degradation by the proteasome [43]. Under hypoxic conditions or conditions where HIF $\alpha$-subunits are otherwise stabilized, the inducible HIF $\alpha$-subunits translocate to the nucleus where they form transcriptionally active heterodimers with constitutively expressed HIF $\alpha$-subunits [44]. Activation of the hypoxia signaling pathway is associated with increased activation of the EMT program, increased cell motility and adoption of stem-like traits and is thus an attractive therapeutic target for solid tumors [27, 35, 41, 42, 45-49].

Our data demonstrate that hypoxia is a potent enhancer of mesenchymal transition and cell motility in GBM. These events can be significantly attenuated by treatment with a pharmacologic inhibitor of HIFs. Given that anti-angiogenic therapy can be associated with an increase in intratumoral hypoxia, these findings provide a mechanism for the observed non-enhancing progression of tumor and the increase in frequency of secondary gliosarcoma transformation following bevacizumab therapy. These data offer the possibility that adjuvant therapy with a HIF inhibitor can delay GBM progression during anti-angiogenic therapy.

\section{MATERIALS AND METHODS}

\section{Human tissue collection}

Surgical specimens from patient 1 were obtained from the Department of Neurosurgery at Huashan Hospital of Fudan University, Shanghai, China. Informed consent was obtained according to Institutional Review Board at Huashan Hospital. Brain autopsies of patients 2 and 3 were performed at The Ohio State University and tissue was obtained through The Ohio State University Department of Pathology. Informed consent was obtained from both patients and approved by the Institutional Review Board of the Office of Responsible Research Practices at The Ohio State University Wexner Medical Center. All specimens were subjected to fixation in $10 \%$ formalin and subsequent paraffin blocking. $5 \mu \mathrm{m}$-thick sections were obtained from each paraffin block and utilized for hematoxylin and eosin (H\&E) and immunohistochemical staining.

\section{HIF knockdown and gain-of-function conditions}

Small-interfering RNA and oligonucleotides against human HIF-1 $\alpha$, human HIF- $2 \alpha$, rat HIF- $1 \alpha$ and rat HIF- $2 \alpha$ and hemagglutinin-tagged gain-of-function constructs were purchased from Sigma-Aldrich (St. Louis, MO). Sequences are listed in Table S1. Cells were transfected with siRNA at a concentration of $75 \mathrm{nM}$ using Lipofectamine 2000 Transfection Reagent (Life Technologies, Carlsbad, CA). Pharmacologic inhibition of HIFs was achieved using an inhibitor of HIF1 $\alpha$ mediated transcription (methyl-3-[[2-[4-(2-adamantyl) 
phenoxy]acetyl]amino]-4-hydroxybenzoate) (Santa Cruz Biotechnology, Santa Cruz, CA) or HIF2 $\alpha$ translation (Methyl-3-(2-(cyano(methylsulfonyl)methylene)

hydrazino)thiophene-2-carboxylate) (Merck Millipore, Darmstadt, Germany) at a concentration of $30 \mu \mathrm{M}$ in DMSO.

\section{Microfluidic chip construction}

The microfluidic chip consisted of a bilayer of polydimethylsiloxane (PDMS) and glass substrate. All chips were designed using an SU8-2035 negative photoresistor (Micro Chem Corp., Newton, MA) molded from a master PDMS layer. Negative chip molds were spun onto a glass wafer and patterned photolithographically in duplicate $(100 \mathrm{~mm}$ thickness for lower layer and $190 \mu \mathrm{m}$ thickness for upper layer), producing unique microstructures with different heights. PDMS base and curing agent (Sylgard Silicone elastomer 184, Dow Corning Corp., Washington, D.C.) were mixed thoroughly $10: 1$ by mass, degassed under vacuum and poured onto the master. The mold curing process was conducted for $1 \mathrm{~h}$ at $80^{\circ} \mathrm{C}$. After cooling, the PDMS layer was gently peeled off of the master and trimmed to size. Inlet and outlet holes were created by punching through the PDMS with a razor-sharp punch. The PDMS mold was decontaminated with oxygen plasma for $15 \mathrm{~s}$, bonded to a glass slide and sterilized with UV light for $30 \mathrm{~m}$. Rat Tail High-Concentration Type-I Collagen solution (BD Biosciences, Franklin Lakes, NJ) was compounded according to an alternate gelation procedure, aseptically added into collagen chamber of the chip and allowed to gel at $37^{\circ} \mathrm{C}$ for $30 \mathrm{~m}$.

\section{Microfluidic chip invasion assay}

Cells were seeded into the main channel of the microfluidic chip at a density of $5 \times 10^{4}$ cells $/ \mathrm{cm}^{2}$ with medium containing $10 \%$ FBS. The chip was then turned on its side for $5 \mathrm{~m}$ to allow the cells to adhere to the surface of the gel. Each chip was then incubated for either $24 \mathrm{~h}$ at $37^{\circ} \mathrm{C}, 21 \% \mathrm{O}_{2}, 5 \% \mathrm{CO}_{2}$ in a humidified incubator (normoxic condition) or at $37^{\circ} \mathrm{C}$ in an electric microscope stage incubation chamber (Okolab, Ottaviano, Italy) flushed with a gas mixture of $1 \% \mathrm{O}_{2}, 5 \% \mathrm{CO}_{2}, 94 \% \mathrm{~N}_{2}$ or $0.2 \% \mathrm{O} 2,5 \% \mathrm{CO} 2,94 \% \mathrm{~N} 2$ (hypoxic conditions). Cells were allowed to invade for $24 \mathrm{~h}$, and images were recorded every $6 \mathrm{~h}$ by an Olympus IX71 fluorescence microscope equipped with a CCD digital camera (Olympus, Tokyo, Japan). After $24 \mathrm{~h}$, each chip was stained with primary antibody and prepared for immunofluorescent imaging as described above.

\section{ACKNOWLEDGEMENTS}

This work was supported by the National Nature Science Foundation of China (grant nos. 91227123 and 11161160552), Key Projects in the National Science \& Technology Pillar Program in the Twelfth Five-Year Plan Period of China (grant nos. 2012BAK02B00 and 2012BAK02B03), Intramural Research Program at the National Institutes of Health (NIH), National Cancer Institute, and the NIH Medical Research Scholars Program, a public-private partnership supported jointly by the NIH and generous contributions to the Foundation for the NIH through Pfizer, Inc., The Doris Duke Charitable Foundation, The Alexandria Real Estate Equities, Inc. and Mr. and Mrs. Joel S. Marcus, and the Howard Hughes Medical Institute, as well as other private donors. For a complete list, please visit the Foundation website at: http:// fnih.org/work/education-training-0/medical-researchscholars-program.

\section{CONFLICTS OF INTEREST STATEMENT}

The authors declare no conflicts of interest.

\section{Editorial note}

This paper has been accepted based in part on peerreview conducted by another journal and the authors' response and revisions as well as expedited peer-review in Oncotarget.

\section{REFERENCES}

1. Wen PY and Kesari S. Malignant gliomas in adults. The New England journal of medicine. 2008; 359(5):492-507.

2. Vredenburgh JJ, Desjardins A, Herndon JE, 2nd, Dowell JM, Reardon DA, Quinn JA, Rich JN, Sathornsumetee S, Gururangan S, Wagner M, Bigner DD, Friedman AH and Friedman HS. Phase II trial of bevacizumab and irinotecan in recurrent malignant glioma. Clinical cancer research : an official journal of the American Association for Cancer Research. 2007; 13(4):1253-1259.

3. Friedman HS, Prados MD, Wen PY, Mikkelsen T, Schiff D, Abrey LE, Yung WK, Paleologos N, Nicholas MK, Jensen R, Vredenburgh J, Huang J, Zheng M and Cloughesy T. Bevacizumab alone and in combination with irinotecan in recurrent glioblastoma. Journal of clinical oncology : official journal of the American Society of Clinical Oncology. 2009; 27(28):4733-4740.

4. Lai A, Tran A, Nghiemphu PL, Pope WB, Solis OE, Selch M, Filka E, Yong WH, Mischel PS, Liau LM, Phuphanich S, Black K, Peak S, Green RM, Spier CE, Kolevska T, et al. Phase II study of bevacizumab plus temozolomide during and after radiation therapy for patients with newly diagnosed glioblastoma multiforme. Journal of clinical 
oncology : official journal of the American Society of Clinical Oncology. 2011; 29(2):142-148.

5. Brem S, Cotran R and Folkman J. Tumor angiogenesis: a quantitative method for histologic grading. Journal of the National Cancer Institute. 1972; 48(2):347-356.

6. Salmaggi A, Eoli M, Frigerio S, Silvani A, Gelati M, Corsini E, Broggi G and Boiardi A. Intracavitary VEGF, bFGF, IL-8, IL-12 levels in primary and recurrent malignant glioma. Journal of neuro-oncology. 2003; 62(3):297-303.

7. Kreisl TN, Kim L, Moore K, Duic P, Royce C, Stroud I, Garren N, Mackey M, Butman JA, Camphausen K, Park J, Albert PS and Fine HA. Phase II trial of single-agent bevacizumab followed by bevacizumab plus irinotecan at tumor progression in recurrent glioblastoma. Journal of clinical oncology : official journal of the American Society of Clinical Oncology. 2009; 27(5):740-745.

8. Folkman J. Angiogenesis: an organizing principle for drug discovery? Nature reviews Drug discovery. 2007; 6(4):273286.

9. Vredenburgh JJ, Desjardins A, Herndon JE, 2nd, Marcello J, Reardon DA, Quinn JA, Rich JN, Sathornsumetee S, Gururangan S, Sampson J, Wagner M, Bailey L, Bigner DD, Friedman AH and Friedman HS. Bevacizumab plus irinotecan in recurrent glioblastoma multiforme. Journal of clinical oncology : official journal of the American Society of Clinical Oncology. 2007; 25(30):4722-4729.

10. Lonser RR YI. (2012). Bevacizumab Treatment in Glioblastoma Patients is Associated with an Increased Development of Secondary Gliosarcoma. 80th Annual Scientific Meeting of the American Association of Neurological Surgeons. Miami.

11. Bergers G and Hanahan D. Modes of resistance to antiangiogenic therapy. Nature reviews Cancer. 2008; 8(8):592603.

12. Blagosklonny MV. Antiangiogenic therapy and tumor progression. Cancer cell. 2004; 5(1):13-17.

13. Harris AL. Hypoxia--a key regulatory factor in tumour growth. Nature reviews Cancer. 2002; 2(1):38-47.

14. Hockel M and Vaupel P. Biological consequences of tumor hypoxia. Seminars in oncology. 2001; 28(2 Suppl 8):36-41.

15. Talks KL, Turley H, Gatter KC, Maxwell PH, Pugh CW, Ratcliffe PJ and Harris AL. The expression and distribution of the hypoxia-inducible factors HIF-1alpha and HIF-2alpha in normal human tissues, cancers, and tumor-associated macrophages. The American journal of pathology. 2000; 157(2):411-421.

16. Zhong H, De Marzo AM, Laughner E, Lim M, Hilton DA, Zagzag D, Buechler P, Isaacs WB, Semenza GL and Simons JW. Overexpression of hypoxia-inducible factor 1alpha in common human cancers and their metastases. Cancer research. 1999; 59(22):5830-5835.

17. Pennacchietti S, Michieli P, Galluzzo M, Mazzone M, Giordano S and Comoglio PM. Hypoxia promotes invasive growth by transcriptional activation of the met protooncogene. Cancer cell. 2003; 3(4):347-361.

18. Cairns RA, Kalliomaki $\mathrm{T}$ and Hill RP. Acute (cyclic) hypoxia enhances spontaneous metastasis of KHT murine tumors. Cancer research. 2001; 61(24):8903-8908.

19. Garayoa M, Martinez A, Lee S, Pio R, An WG, Neckers L, Trepel J, Montuenga LM, Ryan H, Johnson R, Gassmann $\mathrm{M}$ and Cuttitta F. Hypoxia-inducible factor-1 (HIF-1) upregulates adrenomedullin expression in human tumor cell lines during oxygen deprivation: a possible promotion mechanism of carcinogenesis. Mol Endocrinol. 2000; 14(6):848-862.

20. Rofstad EK, Rasmussen H, Galappathi K, Mathiesen B, Nilsen K and Graff BA. Hypoxia promotes lymph node metastasis in human melanoma xenografts by up-regulating the urokinase-type plasminogen activator receptor. Cancer research. 2002; 62(6):1847-1853.

21. Semenza GL. Targeting HIF-1 for cancer therapy. Nature reviews Cancer. 2003; 3(10):721-732.

22. Staller P, Sulitkova J, Lisztwan J, Moch H, Oakeley EJ and Krek W. Chemokine receptor CXCR4 downregulated by von Hippel-Lindau tumour suppressor pVHL. Nature. 2003; 425(6955):307-311.

23. Lonser RR, Vortmeyer AO, Butman JA, Glasker S, Finn MA, Ammerman JM, Merrill MJ, Edwards NA, Zhuang Z and Oldfield EH. Edema is a precursor to central nervous system peritumoral cyst formation. Annals of neurology. 2005; 58(3):392-399.

24. Aiello LP, George DJ, Cahill MT, Wong JS, Cavallerano J, Hannah AL and Kaelin WG, Jr. Rapid and durable recovery of visual function in a patient with von hippel-lindau syndrome after systemic therapy with vascular endothelial growth factor receptor inhibitor su5416. Ophthalmology. 2002; 109(9):1745-1751.

25. Girmens JF, Erginay A, Massin P, Scigalla P, Gaudric A and Richard S. Treatment of von Hippel-Lindau retinal hemangioblastoma by the vascular endothelial growth factor receptor inhibitor SU5416 is more effective for associated macular edema than for hemangioblastomas. American journal of ophthalmology. 2003; 136(1):194-196.

26. Kalluri R and Weinberg RA. The basics of epithelialmesenchymal transition. The Journal of clinical investigation. 2009; 119(6):1420-1428.

27. Polyak K and Weinberg RA. Transitions between epithelial and mesenchymal states: acquisition of malignant and stem cell traits. Nature reviews Cancer. 2009; 9(4):265-273.

28. Han SP, Kim JH, Han ME, Sim HE, Kim KS, Yoon S, Baek SY, Kim BS and Oh SO. SNAI1 is involved in the proliferation and migration of glioblastoma cells. Cellular and molecular neurobiology. 2011; 31(3):489-496.

29. Kahlert UD, Nikkhah G and Maciaczyk J. Epithelial-tomesenchymal(-like) transition as a relevant molecular event in malignant gliomas. Cancer letters. 2013; 331(2):131-138.

30. Mikheeva SA, Mikheev AM, Petit A, Beyer R, Oxford RG, Khorasani L, Maxwell JP, Glackin CA, Wakimoto H, 
Gonzalez-Herrero I, Sanchez-Garcia I, Silber JR, Horner PJ and Rostomily RC. TWIST1 promotes invasion through mesenchymal change in human glioblastoma. Molecular cancer. 2010; 9:194.

31. Qi S, Song Y, Peng Y, Wang H, Long H, Yu X, Li Z, Fang L, Wu A, Luo W, Zhen Y, Zhou Y, Chen Y, Mai C, Liu Z and Fang W. ZEB2 mediates multiple pathways regulating cell proliferation, migration, invasion, and apoptosis in glioma. PloS one. 2012; 7(6):e38842.

32. Siebzehnrubl FA, Silver DJ, Tugertimur B, Deleyrolle LP, Siebzehnrubl D, Sarkisian MR, Devers KG, Yachnis AT, Kupper MD, Neal D, Nabilsi NH, Kladde MP, Suslov O, Brabletz S, Brabletz T, Reynolds BA, et al. The ZEB1 pathway links glioblastoma initiation, invasion and chemoresistance. EMBO molecular medicine. 2013; 5(8):1196-1212.

33. Yang HW, Menon LG, Black PM, Carroll RS and Johnson MD. SNAI2/Slug promotes growth and invasion in human gliomas. BMC cancer. 2010; 10:301.

34. Yang $\mathrm{J}$ and Weinberg RA. Epithelial-mesenchymal transition: at the crossroads of development and tumor metastasis. Developmental cell. 2008; 14(6):818-829.

35. Chaffer CL, Marjanovic ND, Lee T, Bell G, Kleer CG, Reinhardt F, D'Alessio AC, Young RA and Weinberg RA. Poised chromatin at the ZEB1 promoter enables breast cancer cell plasticity and enhances tumorigenicity. Cell. 2013; 154(1):61-74.

36. Lu KV, Chang JP, Parachoniak CA, Pandika MM, Aghi MK, Meyronet D, Isachenko N, Fouse SD, Phillips JJ, Cheresh DA, Park M and Bergers G. VEGF inhibits tumor cell invasion and mesenchymal transition through a MET/ VEGFR2 complex. Cancer cell. 2012; 22(1):21-35.

37. Chung AS, Wu X, Zhuang G, Ngu H, Kasman I, Zhang J, Vernes JM, Jiang Z, Meng YG, Peale FV, Ouyang W and Ferrara N. An interleukin-17-mediated paracrine network promotes tumor resistance to anti-angiogenic therapy. Nature medicine. 2013; 19(9):1114-1123.

38. Ellis LM and Hicklin DJ. VEGF-targeted therapy: mechanisms of anti-tumour activity. Nature reviews Cancer. 2008; 8(8):579-591.

39. Fujio $\mathrm{Y}$ and Walsh K. Akt mediates cytoprotection of endothelial cells by vascular endothelial growth factor in an anchorage-dependent manner. The Journal of biological chemistry. 1999; 274(23):16349-16354.

40. Gerber HP, McMurtrey A, Kowalski J, Yan M, Keyt BA, Dixit V and Ferrara N. Vascular endothelial growth factor regulates endothelial cell survival through the phosphatidylinositol 3'-kinase/Akt signal transduction pathway. Requirement for Flk-1/KDR activation. The Journal of biological chemistry. 1998; 273(46):3033630343 .

41. Krishnamachary B, Zagzag D, Nagasawa H, Rainey K, Okuyama H, Baek JH and Semenza GL. Hypoxia-inducible factor-1-dependent repression of E-cadherin in von Hippel-
Lindau tumor suppressor-null renal cell carcinoma mediated by TCF3, ZFHX1A, and ZFHX1B. Cancer research. 2006; 66(5):2725-2731.

42. Yang MH, Wu MZ, Chiou SH, Chen PM, Chang SY, Liu CJ, Teng SC and Wu KJ. Direct regulation of TWIST by HIF-1alpha promotes metastasis. Nature cell biology. 2008; 10(3):295-305.

43. Maxwell PH, Wiesener MS, Chang GW, Clifford SC, Vaux EC, Cockman ME, Wykoff CC, Pugh CW, Maher ER and Ratcliffe PJ. The tumour suppressor protein VHL targets hypoxia-inducible factors for oxygen-dependent proteolysis. Nature. 1999; 399(6733):271-275.

44. Wang GL, Jiang BH, Rue EA and Semenza GL. Hypoxiainducible factor 1 is a basic-helix-loop-helix-PAS heterodimer regulated by cellular $\mathrm{O} 2$ tension. Proceedings of the National Academy of Sciences of the United States of America. 1995; 92(12):5510-5514.

45. Brat DJ, Castellano-Sanchez AA, Hunter SB, Pecot M, Cohen C, Hammond EH, Devi SN, Kaur B and Van Meir EG. Pseudopalisades in glioblastoma are hypoxic, express extracellular matrix proteases, and are formed by an actively migrating cell population. Cancer research. 2004; 64(3):920-927.

46. Gort EH, Groot AJ, van der Wall E, van Diest PJ and Vooijs MA. Hypoxic regulation of metastasis via hypoxiainducible factors. Current molecular medicine. 2008; 8(1):60-67.

47. Li Z, Bao S, Wu Q, Wang H, Eyler C, Sathornsumetee S, Shi Q, Cao Y, Lathia J, McLendon RE, Hjelmeland AB and Rich JN. Hypoxia-inducible factors regulate tumorigenic capacity of glioma stem cells. Cancer cell. 2009; 15(6):501513.

48. Seidel S, Garvalov BK, Wirta V, von Stechow L, Schanzer A, Meletis K, Wolter M, Sommerlad D, Henze AT, Nister M, Reifenberger G, Lundeberg J, Frisen J and Acker T. A hypoxic niche regulates glioblastoma stem cells through hypoxia inducible factor 2 alpha. Brain : a journal of neurology. 2010; 133(Pt 4):983-995.

49. Soeda A, Park M, Lee D, Mintz A, Androutsellis-Theotokis A, McKay RD, Engh J, Iwama T, Kunisada T, Kassam AB, Pollack IF and Park DM. Hypoxia promotes expansion of the CD133-positive glioma stem cells through activation of HIF-1alpha. Oncogene. 2009; 28(45):3949-3959. 